\title{
Prevalence of Developmental Dental Anomalies of Number and Size in Indian Population According to Age and Gender
}

\author{
Arvind Jain ${ }^{1}$, Ashish Saxena ${ }^{2}$, Sandhya Jain $^{3}$, Ajay Pratap Singh Parihar ${ }^{4}$, Amit Rawat ${ }^{5}$
}

\begin{abstract}
Introduction: Dental anomalies arise due to genetic and environmental factors in the morphodifferentiation stage of odontogenesis lead to alteration in the number and size of the tooth as well as the root. ${ }^{1-3}$ The knowledge of their prevalence and the extent of involvement can provide valuable information for phylogenic and genetic studies and also help in the understanding of differences among the population and between various population groups. ${ }^{4}$ We aim to identify the prevalence and distribution of such anomalies according to age and gender. The acquired details of cases will further help the dental clinicians to understand their etiology which can further facilitate their diagnosis and effective management. Also, timely intervention can be achieved.

Materials and methods: Retrospective study of 4,000 subjects (equal proportion of males and female) of age range from 10 to 40 years were studied. Their radiographs, dental casts, and clinical findings were evaluated for number and size developmental dental anomaly.

Results: Incidence of overall 331 cases (8.27\%) of number and size developmental dental anomalies were recorded with 173 (8.6\%) males and $158(7.9 \%)$ females. Hypodontia was the most frequently found dental anomaly in both males (4.9\%) and females (4.4\%) followed by hyperdontia and supernumerary roots. Microdontia was the most frequently found size anomaly in both males (1.6\%) and females (1.9\%).

Conclusion: Hypodontia (4.7\%) is the most frequently found numeral anomaly in both males and females. Intergroup study shows a significant statistical difference in cases of hypodontia in the 10-25 years of age-group (6.2\%) with a $p$ value $\leq 0.00001$.

Keywords: Anomaly, Developmental dental anomalies, Hypodontia, Numeral anomaly, Size anomaly.

International Journal of Clinical Pediatric Dentistry (2021): 10.5005/jp-journals-10005-1980
\end{abstract}

\section{INTRODUCTION}

Dental developmental anatomical variants either structural or morphological are most often associated with oral health problems. Developmental alterations of teeth are seen in form of a number (hypodontia and hyperdontia); size (microdontia and macrodontia); shape (gemination, fusion, concrescence, accessory cusps, dens invaginatus, ectopic enamel, taurodontism, hypercementosis, accessory roots, dilaceration); and structure (amelogenesis imperfecta, dentinogenesis imperfecta, dentin dysplasia, regional odontodysplasia). ${ }^{5}$ Developmental dental anomalies can occur as a result of genetic or environmental factors or a combination of both of them and could be observed as an evolutionary trend. ${ }^{1}$ The development of anomalies in tooth number, shape, and position results from disturbances that occur during the morphodifferentiation stage of development. ${ }^{2,3}$ Changes in the pattern of tooth eruption can affect the organization of the dental arches and cause malocclusion. All of them may modify the surgical treatment, endodontics, and restorative dental procedures. ${ }^{6}$ The pattern of such variation in the Indian population is very significant for dental practitioners throughout India. There are varied results of published studies about the prevalence of dental anomalies, which further need research to help clarify the frequency and distribution of dental anomalies based on gender and age. Besides this, limited studies have been done to identify the changes in the current trends of prevalence of dental developmental anatomical variants. Hence, the present study was conducted to assess the prevalence of two types (number and size) and their subtypes of dental anomalies and identify their current pattern so that effective change in the diagnosis and management can be acted upon accordingly.
${ }^{1}$ Department of Conservative Dentistry and Endodontics, Government College of Dentistry, Indore, Madhya Pradesh, India

${ }^{2}$ Department of Pediatric Dentistry, Government College of Dentistry, Indore, Madhya Pradesh, India

${ }^{3}$ Department of Orthodontics, Government College of Dentistry, Indore, Madhya Pradesh, India

${ }^{4}$ Department of Oral Medicine, Government College of Dentistry, Indore, Madhya Pradesh, India

${ }^{5}$ Department of Oral and Maxillofacial Surgery, Government College of Dentistry, Indore, Madhya Pradesh, India

Corresponding Author: Arvind Jain, Department of Conservative Dentistry and Endodontics, Government College of Dentistry, Indore, Madhya Pradesh, India, Phone: +91 9826581598, e-mail: drarvindendo@gmail.com

How to cite this article: Jain A, Saxena A, Jain S, et al. Prevalence of Developmental Dental Anomalies of Number and Size in Indian Population According to Age and Gender. Int J Clin Pediatr Dent 2021;14(4):531-536.

Source of support: Nil

Conflict of interest: None

\section{Materials and Methods}

This random observational and retrospective study was conducted in the patients attending the routine OPD of Government College of Dentistry and from their medical records. Patients born and living in India were included in the study. A total of 4,000 cases including both males and females in equal proportion were included in the study. Intraoral examination findings, dental casts, and radiographs

() The Author(s). 2021 Open Access This article is distributed under the terms of the Creative Commons Attribution 4.0 International License (https://creativecommons. org/licenses/by-nc/4.0/), which permits unrestricted use, distribution, and non-commercial reproduction in any medium, provided you give appropriate credit to the original author(s) and the source, provide a link to the Creative Commons license, and indicate if changes were made. The Creative Commons Public Domain Dedication waiver (http://creativecommons.org/publicdomain/zero/1.0/) applies to the data made available in this article, unless otherwise stated. 
of cases ranging from 10 to 40 years of age were taken and reviewed after diving them into two study groups. First study group ranging from 10 to 25 years of age and the second group from 25 to 40 years assuming that dentition is supposedly complete by 25 years of age. Also, a comprehensive clinical examination along with a history of extraction, exfoliation, injury, etc., was taken to identify the presence of hyperdontia, hypodontia, macro-, and microdontia along with radiographic evaluation. Third molars were not included for evaluation.

\section{Exclusion Criteria}

- Patients of age $\leq 10$ and $\geq 40$ years were excluded from the study.

- Patients with syndromes that could cause developmental dental anomaly such as Down's syndrome, cleidocranial dysostosis, and ectodermal dysplasia.

- Cleft lip and palate, tooth extracted due to caries, trauma or for orthodontic reasons, large restorations preventing observation of crown morphology and incompletely formed roots.

A family and dental history involved questions about the primary dentition and details such as color, tooth wear, abscess formation, tooth mobility, and loss of teeth were recorded.

The selection criteria of the samples included the patients who were not diagnosed with any serious childhood illnesses and systemic syndromes. Patients with no history of previous orthodontic treatment were included in this study.

Criteria for selection of various anomalies and their subtypes.

\section{Number Anomaly}

\section{Hyperdontia}

Presence of extra tooth (one or more) of any size either erupted or non-erupted confirmed radiographically or clinically were noted. Mesiodens were also included in it.

\section{Hypodontia}

Absence of any tooth (one or more) confirmed radiographically or clinically were noted.

\section{Supernumerary Roots}

Confirmed radiographically by the presence of extra roots than usual.

\section{Size Anomaly \\ Microdontia and Macrodontia}

It was confirmed by clinical observation of the presence of abnormally small teeth as microdontia and abnormally large teeth as macrodontia.

\section{Short Root}

Congenital short root is confirmed radiographically with the presence of abnormally short root than normal. Acquired short roots due to resorption, trauma, etc., are excluded via careful and thorough clinical and radiographic evaluation.

\section{Results}

The study group comprised of equal proportion of males and females in both the groups, each consisting of 2,000 subjects. No significant statistical difference of mean and standard deviation (SD) of overall ages of males and females were present. The mean \pm SD of age among males was $25.1 \pm 8.07$ and that among females was $24.75 \pm 8.01$ with the age range from 10 to 40 years. Among the 4,000 subjects evaluated, a total of 331 (8.27\%) had selected number and size developmental dental anomalies which included $173(8.6 \%)$ males and 158 (7.9\%) females (Table 1). No cases of more than two dental anomalies were present.

The frequency and distribution of tooth and root number and size anomalies according to gender are shown in Table 2 . No cases of oligodontia and anodontia were found. Hypodontia was the most frequently found dental anomaly in both males (4.9\%) and females (4.4\%) followed by hyperdontia (males-1.2\%, females-1.05\%) and then by root number anomaly (males- $0.5 \%$, females- $0.3 \%$ ). In all types of dental number anomalies, male preponderance was found with a non-significant statistical difference with females. On studying size anomaly, microdontia was the most frequently found size anomaly in both males (1.6\%) and females (1.9\%) followed by short root (males- $0.3 \%$, females- $0.1 \%$ ). Microdontia was rarely present. A single case was detected in a female (0.02\%).

The frequency and distribution of tooth and root number and size anomalies according to age-groups is shown in Table 3. The frequency of number anomaly was more in the age-group of 10-25 years ( 8.15 vs $4.4 \%$ ), while size anomaly was found to have a higher incidence in the $25-40$ years of age-group (2.1 vs $1.9 \%$ ). All subtypes of number anomalies of tooth and root in the younger age-group of $10-25$ years viz. hypodontia (6.2\%), hyperdontia (1.35\%), and supernumerary root $(0.6 \%)$ show higher incidence in the younger age-group of 10-25 years as compared to the older age-group of 25-40 years. The latter group shows a comparatively less incidence of hypodontia (3.2\%), hyperdontia (0.9\%), and supernumerary root $(0.3 \%)$. Higher incidence of congenitally missing tooth (hypodontia-6.2\%) in the age-group of 10-25 years was found to be statistically significant with a $p$ value of 0.00001 .

Microdontia $(1.9 \%)$ and macrodontia $(0.05 \%)$ were more prevalent in 25-40 years while short root (0.35) was found to be more prevalent in the younger group of 10-25 years with no statistically significant relation.

The distribution of congenitally absent teeth (hypodontia) in both males and females in both the age-group of 10-25 and 25-40 years is shown in Table 4. Males (4.95\%) have an overall higher prevalence of missing teeth as compared to females (4.45\%). Also, the younger age-group belonging to $10-25$ years $(6.2 \%)$ have a

Table 1: Distribution of developmental dental anomaly of number and size by gender and age

\begin{tabular}{|c|c|c|c|c|c|c|c|c|c|}
\hline \multirow[b]{2}{*}{$\begin{array}{l}\text { Description of variable } \\
\text { dental anomaly }\end{array}$} & \multicolumn{3}{|c|}{ Age $10-25$ years $(N=2,000)$} & \multicolumn{3}{|c|}{ Age $25-40$ years $(n=2,000)$} & \multicolumn{3}{|c|}{$N=4,000$} \\
\hline & $\begin{array}{l}\text { Male } \\
(n=1,000)\end{array}$ & $\begin{array}{l}\text { Female } \\
(n=1,000)\end{array}$ & $\begin{array}{l}\text { Total } \\
(n=2,000)\end{array}$ & $\begin{array}{l}\text { Male } \\
(n=1,000)\end{array}$ & $\begin{array}{l}\text { Female } \\
(n=1,000)\end{array}$ & $\begin{array}{l}\text { Total } \\
(n=2,000)\end{array}$ & $\begin{array}{l}\text { Male } \\
(n=2,000)\end{array}$ & $\begin{array}{l}\text { Female } \\
(n=2,000)\end{array}$ & $\begin{array}{l}\text { Total } \\
(n=4,000)\end{array}$ \\
\hline Anomaly absent & 907 & 918 & 1,825 & 920 & 924 & 1,844 & 1,827 & 1,842 & 3,669 \\
\hline One dental anomaly & 101 & 92 & 193 & 65 & 62 & 127 & 166 & 154 & 320 \\
\hline Two dental anomaly & 5 & 3 & 8 & 2 & 1 & 3 & 7 & 4 & 11 \\
\hline $\begin{array}{l}\text { Total cases of dental } \\
\text { anomaly }\end{array}$ & $106(10.6 \%)$ & $95(9.5 \%)$ & $201(10.05 \%)$ & $67(6.7 \%)$ & $63(6.3 \%)$ & $130(6.5 \%)$ & $173(8.6 \%)$ & $158(7.9 \%)$ & $331(8.27 \%)$ \\
\hline
\end{tabular}


higher incidence than the older group with an age range of 25-40 years (3.2\%). Maxillary lateral incisor is the most commonly missing teeth $(0.925 \%)$ followed by maxillary premolar $(0.825 \%)$.

\section{Discussion}

Our epidemiological study is unique and comprehensive with the prime agenda to document the prevalence of various number and size anomalies specifically of tooth and root with their gender distribution and age-group variation. It is imperative to compare our present findings with other studies as wide variation in the prevalence could exist depending on the chronological age of the sample, regional variation, ethnicity, sample size, etc. Comparative evaluation of the present study with a previous similar study is shown in Table 5.

It shows a wide range of prevalence of the number and size of the tooth in various regions. Very few studies are there for short root and supernumerary root. Apajalahti et al. ${ }^{14}$ in 2002 found the prevalence of short-root anomaly (SRA) as $1.35 \%$ while in our study overall prevalence is $0.2 \%$ in total cases studied. Patients with the anomalous short root are in turn at higher risk of root resorption during orthodontic treatment. ${ }^{15}$

Table 2: Gender distribution of numeral and size developmental dental anomaly

\begin{tabular}{|c|c|c|c|c|}
\hline & Males $(n=2,000), N \%$ & Females $(n=2,000), N \%$ & Total $(n=4,000), N \%$ & $p$ value \\
\hline \multicolumn{5}{|l|}{ Number anomaly } \\
\hline Hypodontia & $99(4.9 \%)$ & $89(4.4 \%)$ & $188(4.7 \%)$ & 0.45 (NS) \\
\hline Hyperdontia & $24(1.2 \%)$ & $21(1.05 \%)$ & 45 (1.125\%) & 0.65 (NS) \\
\hline Supernumerary root & $11(0.5 \%)$ & $7(0.3 \%)$ & $18(0.4 \%)$ & 0.34 (NS) \\
\hline Total numeral anomalies & $134(6.7 \%)$ & $117(5.8 \%)$ & $251(6.27 \%)$ & 0.26 (NS) \\
\hline \multicolumn{5}{|l|}{ Size anomaly } \\
\hline Microdontia & $33(1.6 \%)$ & $38(1.9 \%)$ & $71(1.8 \%)$ & 0.54 (NS) \\
\hline Macrodontia & 0 & $1(0.05 \%)$ & $1(0.02 \%)$ & - \\
\hline Short root & $6(0.3 \%)$ & $2(0.1 \%)$ & $8(0.2 \%)$ & 0.15 (NS) \\
\hline Total size anomalies & 39 (1.9\%) & $41(2.05 \%)$ & $80(2 \%)$ & 0.82 (NS) \\
\hline
\end{tabular}

Chi-square test

Table 3: Age distribution of numeral and size developmental dental anomaly

\begin{tabular}{lllll}
\hline & $10-25$ years $(n=2,000), N \%$ & $25-40$ years $(n=2,000), N \%$ & Total $(n=4,000)$, N\% & $p$ value \\
\hline $\begin{array}{l}\text { Number anomaly } \\
\text { Hypodontia }\end{array}$ & $124(6.2 \%)$ & $64(3.2 \%)$ & $188(4.7 \%)$ & $0.00001($ significant) \\
Hyperdontia & $27(1.35 \%)$ & $18(0.9 \%)$ & $45(1.125 \%)$ & 0.17 (NS) \\
Supernumerary root & $12(0.6 \%)$ & $6(0.3 \%)$ & $18(0.4 \%)$ & 0.15 (NS) \\
Total numeral anomalies & $163(8.15 \%)$ & $88(4.4 \%)$ & $251(6.25 \%)$ & 0.00001 (significant) \\
Size anomaly & & & & \\
Microdontia & $32(1.6 \%)$ & $39(1.9 \%)$ & $71(1.8 \%)$ & $0.4(\mathrm{NS})$ \\
Macrodontia & 0 & $1(0.05 \%)$ & $1(0.02 \%)$ & - \\
Short root & $6(0.3 \%)$ & $2(0.1 \%)$ & $8(0.2 \%)$ & 0.15 (NS) \\
Total size anomalies & $38(1.9 \%)$ & $42(2.1 \%)$ & $80(2 \%)$ & 0.65 (NS) \\
\hline
\end{tabular}

Table 4: Hypodontia (missing teeth) distribution in dental arch

\begin{tabular}{lcclcc} 
Teeth & Male $(n=2,000)$ & Female $(n=2,000)$ & Total $(\mathrm{N} \% n=4,000)$ & $\begin{array}{l}\text { Age-group 10-25 years } \\
(n=2,000)\end{array}$ & $\begin{array}{c}\text { Age-group 25-40 years } \\
(n=2,000)\end{array}$ \\
\hline Maxillary central incisor & 3 & 2 & $5(0.125 \%)$ & 3 & 2 \\
Maxillary lateral incisor & 21 & 16 & $37(0.925 \%)$ & 23 & 14 \\
Mandibular central incisor & 2 & 2 & $4(0.1 \%)$ & 3 & 1 \\
Mandibular lateral incisor & 15 & 14 & $29(0.725 \%)$ & 18 & 11 \\
Maxillary canines & 12 & 11 & $23(0.575 \%)$ & 14 & 9 \\
Mandibular canines & 10 & 9 & $19(0.475 \%)$ & 12 & 7 \\
Maxillary premolar & 18 & 15 & $33(0.825 \%)$ & 24 & 9 \\
Mandibular premolar & 15 & 13 & $28(0.7 \%)$ & 21 & 7 \\
Maxillary molar & 2 & 5 & $7(0.175 \%)$ & 4 & 3 \\
Mandibular molars & 1 & 2 & $3(0.075 \%)$ & 2 & 1 \\
Total & $99(4.95 \%)$ & $89(4.45 \%)$ & $188(4.7 \%)$ & $124(6.2 \%)$ & $64(3.2 \%)$ \\
\hline
\end{tabular}




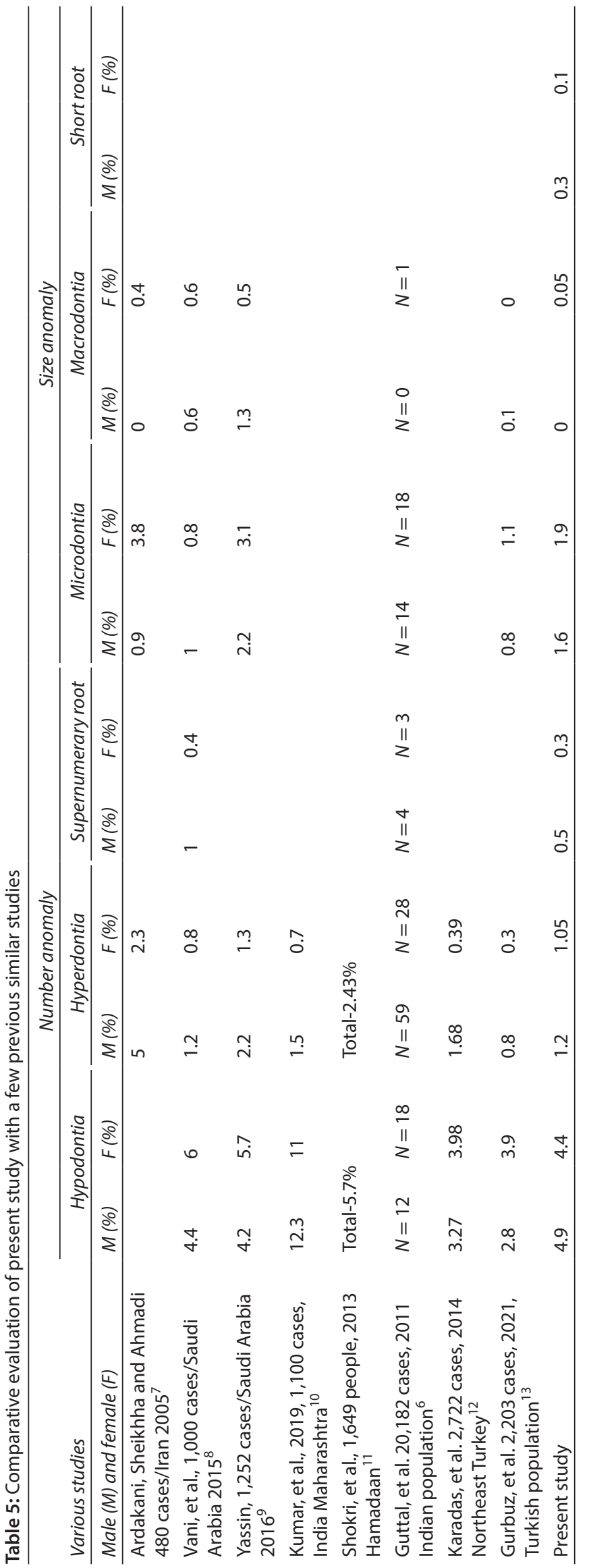


Prevalence of Developmental Dental Anomalies of Number and Size in Indian Population According to Age and Gender

The prevalence of supernumerary roots was studied in the Odisha population in India in 2017 and found to be $0.83 \%{ }^{16}$ while in our study its total prevalence is $0.4 \%$. Schäfer et al. ${ }^{17}$ in 2009 found $1.35 \%$ of three rooted mandibular first molars in 1,024 patients. Out of 524 patients, 260 females and 264 males total 7 ( 4 males and 3 females) were having three rooted mandibular first molars. Thus, the incidence was $1.52 \%$ for men and $1.15 \%$ for women. While in our study out of 4,000 cases (2,000 males and 2,000 females) only 13 cases ( 8 males and 5 females) of three rooted mandibular first molar were present. Thus, $0.4 \%$ males and $0.25 \%$ female's incidence was found in our study.

The total incidence of hypodontia in our study was $4.7 \%$ with maxillary lateral incisor (0.92\%) most commonly found missing tooth followed by maxillary premolar (0.82\%). A study of Shokri et al. ${ }^{11}$ in the age-group of 7-35 years also found the maxillary lateral incisor to be the most commonly found missing tooth followed by mandibular premolars while Celikoglu et al. ${ }^{18}$ found maxillary lateral incisors (46.5\%) to be most frequent congenitally missing teeth in the Turkish orthodontic patient population, followed by mandibular second premolars (22.5\%) and mandibular central incisors (13.4\%).

On comparing the frequency with age-group studies wide variations were found. It may be due to variation in sample size along with variation in age-group considered for studies. In our study, frequency of hypodontia (6.2\%) and hyperdontia (1.35\%) in the $10-25$ years of age-group while Goncalves-Filho et al. ${ }^{19}$ found $11.11 \%$ of hypodontia and $6.79 \%$ of hyperdontia in the age-group up to 12 years. Size anomalies in our study reflect a prevalence of $1.6 \%$ microdontia and no cases of macrodontia in the 10 to 25 years of age-group. Goncalves-Filho et al. in his study in north Brazialian population found $2.47 \%$ microdontia and $0.62 \%$ macrodontia in age-group up to 12 years. Ezoddini et al.' $\mathrm{s}^{7}$ study on age-groups up to 20 years revealed an incidence of 3.2\% supernumerary teeth, $2 \%$ microdontia, and $0.0 \%$ macrodontia. Thus, our study is intermediate between the above two studies.

In age-groups ranging from 25 to 40 years, our study reveals a prevalence of $3.2 \%$ hypodontia, $0.9 \%$ hyperdontia, $1.9 \%$ microdontia, and $0.05 \%$ macrodontia. Study on age-group above 12 years by Goncalves-Filho et al. ${ }^{19}$ shown incidence of $3.8 \%$ hypodontia, $5.38 \%$ hyperdontia, $6.96 \%$ microdontia, and $0.63 \%$ macrodontia. Guttal et al.'s ${ }^{6}$ study on age-group above 20 years revealed an incidence of $3.9 \%$ supernumerary teeth, $3 \%$ microdontia, and $0.4 \%$ macrodontia.

Genetic and environmental have influential elements in the genesis of supernumerary teeth, hypodontia, megadontia, and microdontia. Also, these anomalies tend to be associated with one another. ${ }^{20}$ Tooth number and size are influenced by initiation and morphogenic stages of odontogenesis. The molecular evidence of repetitive signaling throughout initiation and morphogenesis is presented clinically in the form of anomalies of number and size. ${ }^{21}$ Microdontia is a frequently observed feature of hypodontia in case reports and case series. ${ }^{22}$ It is also reported that nearly $46 \%$ of individuals with tooth agenesis also have short roots of other permanent teeth. ${ }^{23}$ Generalized spacing and rotations of teeth adjacent to missing mandibular second premolars are also commonly observed features. ${ }^{24}$

Incidence and association of number and size developmental dental anomalies are quite variable within the population. An awareness of various anomalies and distribution among various gender and age-groups is significant to all dental practitioners for timely management.

\section{Conclusion}

Within the limitation, our study documented prevalence and distribution of variable subtypes of number and size anomalies of tooth and root according to age and gender. Hypodontia (4.7\%) is the most frequently found numeral anomaly in both males and females. Besides this, intergroup statistical difference in the prevalence of hypodontia in $10-25$ years $(6.2 \%)$ as compared to $25-40$ years (3.2\%) shows a significant difference with a $p$ value $\leq 0.00001$ with $\leq 95 \%$ confidence limit. Hyperdontia was seen more common in the anterior region than in the premolar and molar regions with an insignificant difference in our study. Timely diagnosis of dental anomalies can restrict to a great extent the esthetic, orthodontic, and periodontal problems. Awareness of the prevalence and distribution of the tooth and root developmental anomalies related to the number and size of will help clinicians to detect these anomalies at early stages and timely intervention can be executed.

\section{References}

1. Primožič J, Farčnik F, Ovsenik M. Places in the dental arch that show a greater variability in tooth number, shape and position - a prevalence study. Arch Oral Biol 2012;57(6):744-748. DOI: 10.1016/j. archoralbio.2011.11.009.

2. Altug-Atac AT, Erdem D. Prevalence and distribution of dental anomalies in orthodontic patients. Am J Orthod Dentofacial Orthop 2007;131(4):510-514. DOI: 10.1016/j.ajodo.2005.06.027.

3. Kazanci F, Celikoglu M, Miloglu O, et al. Frequency and distribution of developmental anomalies in the permanent teeth of a Turkish orthodontic patient population. J Dent Sci 2011;6(2):82-89. DOI: 10.1016/j.jds.2011.03.003.

4. Yaacob $H$, Nambiar $P$, Naidu MDK. Racial characteristics of human teeth with special emphasis on the Mongoloid dentition. Malaysian J Pathol 1996;18(1):1-7.

5. Neville BW, Damm DD, Allen CM, et al. Oral and maxillofacial pathology. In Oral and maxillofacial pathology. 16th ed., St. Louis, MO: Elsevier; 2016.

6. Guttal KS, Naikmasur VG, Bhargava P, et al. Frequency of developmental dental anomalies in the Indian population. Eur J Dent. 2010;4(3):263-269. DOI: 10.1055/s-0039-1697838.

7. Ezoddini AF, Sheikhha MH, Ahmadi H. Prevalence of dental developmental anomalies: a radiographic study. Community Dent Health 2007;24(3):140-144.

8. Vani NV, Saleh SM, Tubaigy FM, et al. Prevalence of developmental dental anomalies among adult population of Jazan, Saudi Arabia. Saudi J Dent Res 2016;7(1). DOI: 10.1016/j.sjdr.2015.03.003.

9. Yassin SM. Prevalence and distribution of selected dental anomalies among saudi children in Abha, Saudi Arabia. J Clin Exp Dent 2016;8(5):e485-e490. DOI: 10.4317/jced.52870.

10. Kumar D, Datana S, Kadu A, et al. The prevalence of dental anomalies among the Maharashtrian population: a radiographic study. J Dent Def Sect 2020;14(1):11-15. DOI: 10.4103/JODD.JODD_5_19.

11. Shokri A, Poorolajal J, Khajeh S, et al. Prevalence of dental anomalies among 7- to 35-year-old people in Hamadan, Iran in 2012-2013 as observed using panoramic radiographs. Imaging Sci Dent. 2014;44(1):7-13. DOI: 10.5624/isd.2014.44.1.7.

12. Karadas M, Celikoglu M, Akdag MS. Evaluation of tooth number anomalies in a subpopulation of the North-East of Turkey. Eur J Dent. 2014;8(3):337-341. DOI: 10.4103/1305-7456.137641.

13. Gurbuz O, Ersen A, Dikmen B, et al. The prevalence and distribution of the dental anomalies in the Turkish population. J Anat Soc India 2019;68:46-51.

14. Apajalahti S, Hölttä $P$, Turtola L, et al. Prevalence of short-root anomaly in healthy young adults. Acta Odontol Scand 2002;60(1):56-59. DOI: 10.1080/000163502753472014. 
15. Marques LS, Generoso R, Armond MC, et al. Short-root anomaly in an orthodontic patient. Am J Orthod Dentofacial Orthop 2010;138(3):346-348. DOI: 10.1016/j.ajodo.2008.08.037.

16. Goutham B, Bhuyan L, Chinnannavar SN, et al. Prevalence of dental anomalies in Odisha population: a panoramic radiographic study. J Contemp Dent Pract 2017;18(7):549-553. DOI: 10.5005/ jp-journals-10024-2082.

17. Schäfer $E$, Breuer $D$, Janzen S. The prevalence of three-rooted mandibular permanent first molarsin a German population. J Endod 2009;35(2):202-205. DOI: 10.1016/j.joen.2008.11.010.

18. Celikoglu M, Kazanci F, Miloglu O, et al. Frequency and characteristics of tooth agenesis among an orthodontic patient population. Med Oral Patol Oral Cir Bucal 2010;15(5):e797-e801. DOI: 10.4317/medoral. 15.e797.

19. Goncalves-Filho AJ, Moda LB, Oliveira RP, et al. Prevalence of dental anomalies on panoramic radiographs in a population of the state of
Pará, Brazil. Indian J Dent Res 2014;25(5):648-652. DOI: 10.4103/09709290.147115

20. Brook AH. A unifying aetiological explanation for anomalies of human tooth number and size. Arch Oral Biol 1984;29(5):373-378. DOI: 10.1016/0003-9969(84)90163-8.

21. Brook AH, Jernvall J, Smith RN, et al. The dentition: the outcomes of morphogenesis leading to variations of tooth number, size and shape. Aust Dent J. 2014;59(Suppl 1):131-142. DOI: 10.1111/adj.12160.

22. Hobkirk JA, Goodman JR, Jones SP. Presenting complaints and findings in a group of patients attending a hypodontia clinic. British Dental Journal 1994;177(9):337-339. DOI: 10.1038/sj.bdj.4808606.

23. Arte S. Phenotypic and genotypic features of familial hypodonita [Dissertation]. Helsinki, Finland: University of Helsinki; 2001.

24. Baccetti T. A controlled study of associated dental anomalies. Baccetti T Angle Orthod. 1998;68(3):267-274. DOI: 10.1043/00033219(1998)0682.3.CO;2. 